\title{
Espaço social alimentar e sociobiodiversidade em uma comunidade do Vale do Jequitinhonha (MG)
}

\section{Food social space and socio-biodiversity in a community of Vale do Jequitinhonha, Minas Gerais}

Luiza Helena Pedra da Silva ${ }^{1}$

Fabiane Nepomuceno Costa ${ }^{2}$ Nadja Maria Gomes Murta ${ }^{3}$

A riqueza de relações entre populações humanas e a biota presente no Vale do Jequitinhonha confere à região uma elevada sociobiodiversidade. Atualmente, esta encontra-se ameaçada pelas pressões da economia hegemônica, ocasionando perdas de conhecimentos e de práticas tradicionais que envolvem tais recursos. Sobretudo as comunidades rurais e tradicionais têm agravo em seus problemas sociais ao terem impactos em seus conhecimentos e práticas, que se constituem em estratégias de vivência na região. O uso dos recursos vegetais disponíveis no ambiente é uma dessas estratégias que contribui para a segurança alimentar, historicamente desenvolvida pelas populações rurais, mas que se encontram em processo de desuso em decorrência da homogeneização da alimentação. Neste contexto, a presente pesquisa objetivou investigar o espaço social alimentar - em suas dimensões de espaço do comestível, do culinário, da diferenciação social, da temporalidade, dos hábitos e consumo, e sistema alimentar - no distrito de São João da Chapada (Diamantina, em Minas Cerais), com foco no papel das plantas alimentícias espontâneas nesse espaço social alimentar. Sob abordagem qualitativa e quantitativa foram realizadas entrevistas semiestruturadas, caminhadas etnobotânicas, demonstrações culinárias e observação participante - como método etnográfico. A análise dos resultados se deu por análise de conteúdo temática e estatística descritiva. O sistema alimentar de São João da Chapada tem forte vínculo com o território e a autoprodução, sendo gerido pelo trabalho feminino. O conhecimento sobre plantas espontâneas entre os participantes é superior ao seu uso efetivo, em função de aspectos como o aumento do consumo de alimentos antes inacessíveis, e às memórias negativas em relação ao consumo dessas plantas em circunstâncias de escassez. Essa memória afetiva de negação ocorre, sobretudo, para as espécies consumidas nas refeições principais, enquanto para as espécies frutíferas, de consumo de caráter complementar, as memórias são positivas, relacionadas à família e infância. As práticas e os conhecimentos sobre os recursos vegetais não têm sido de interesse pela juventude local, o que ameaça a continuidade dos saberes tradicionais e ambientais. Dadas as particularidades observadas na localidade, é necessário que as ações de fomento à segurança alimentar e nutricional considerem a configuração e as dinâmicas do espaço social alimentar em questão.

Palavras-chave: conhecimento tradicional; plantas comestíveis; recursos vegetais alimentares; São João da Chapada.

Keywords: traditional knowledge; edible plants; green resources; São João da Chapada.

1 Mestre em Saúde, Sociedade e Ambiente pela Universidade Federal dos Vales do Jequitinhonha e Mucuri.

2 Doutora em Ciências Biológicas (Botânica) pela Universidade de São Paulo.

3 Doutora em Ciências Sociais: Antropologia pela Pontifícia Universidade Católica de São Paulo. 